\title{
Pengaruh Metode Inqury Discoveri Learning Terhadap Hasil Belajar PKn Siswa Kelas IV SDN 139 Kecamatan Duampanua Kabupaten Pinrang
}

\author{
Jumiati Nur ${ }^{1)}$ \& Andi Sugiati ${ }^{2)}$ \\ Pendidikan Pancasila dan Kewarganegaraan FKIP Universitas Muhammadiyah Makassar ${ }^{1)}$ \\ Pendidikan Pancasila dan Kewarganegaraan FKIP Universitas Muhammadiyah Makassar 2) \\ jumiatinur@unismuh.ac.id ${ }^{11}$ \& andisugiati@unismuh.ac.id ${ }^{21}$
}

\begin{abstract}
This research is research that want to know difference of result of student learning when given treatment or treatment with not given treatment or treatment to fourth grade student of SDN 139 District of Duampanua Regency of Pinrang, subject of this research is fourth grader student of subject year 2016 subject 32 student. Technical data through pretest and posttest data and observation and analyzed descriptively and hypothesis test. The results showed that the learning of Civics through learning method of Inquiry Discoveri Learning can improve student's learning result of Civitas compared to tampa with method average 61,4 after giving average score 75,4. English learning activities using learning methods. Discover learning Improved learning by seeing students begin to be active and pay attention to taught material, do the job well and correctly, enthusiastic to ask questions to the teacher and answer questions given. Students who just simply imitate at the time doing the task began to appear curiosity how to complete the task given.
\end{abstract}

Keywords: Inquiry Discoveri Learning, Learning Outcomes, Civics

\begin{abstract}
Abstrak. Penelitian ini adalah penelitian eksperimen yang bertujuan untuk mengetahui perbedaan hasil belajar siswa pada saat diberi perlakuan atau treatment dengan tidak diberi perlakuan atau treatment pada murid kelas IV SDN 139 Kecamatan Duampanua Kabupaten Pinrang, subjek penelitian ini adalah murid kelas IV tahun pelajaran 2016 subjek 32 murid. Teknik pengumpulan data melalui Pretest dan Posttest dan observasi dan dianalisis secara deskriptif dan uji hipotesis. Hasil penelitian menunjukkan bahwa pembelajaran PKn melalui metode pembelajaran Inquiry Discoveri Learning dapat meningkatkan hasil belajar PKn murid dibanding dengan tampa menggunakan metode Inquiry Discoveri Learning dengan skor rata-rata 61,4 setelah diberi perlakuan skor rata-rata 75,4 . Aktivitas belajar murid menggunakan metode pembelajaran Inquiry Discoveri Learning mengalami peningkatan dengan melihat murid mulai aktif dan memperhatikan materi yang diajarkan, mengerjakan tugas dengan baik dan benar, antusias untuk mengajukan pertanyaan pada guru dan menjawab pertanyaan yang diberikan. Murid yang awalnya hanya mencontoh pada temannya pada saat mengerjakan tugas mulai muncul rasa ingin tahu bagaimana cara menyelesaikan tugas yang diberikan.
\end{abstract}

Kata kunci: Inquiry Discoveri Learning, Hasil Belajar, PKn 


\section{PENDAHULUAN}

Pendidikan adalah hak bagi setiap insan manusia, tanpa terkecuali karena Negara suda menjamin warganya untuk mendapatkan pendidikan yang layak. Berdasarkan Undangundang NO.20 Tahun 2003 tentang System Pendidikan Nasional. Pada Pasal 1 disebutkan bahwa pendidikan adalah usaha sadar dan terencana untuk mewujudkan suasana belajar dan proses pembelajaran agar peserta didik secara aktif mengembangkan potensi dirinya untuk memiliki kekuatan spiritual keagamaan, pengendalian diri, kepribadian kecerdasan akhlak mulia,moral serta keterampilan yang diperlukan dirinya, masyarakat bangsa dan Negara (Dika Prestama dalam Sukdiknas 2010:2)

Pendidik adalah orang yang selalu dipandang, dicontoh oleh anakdidiknya ataupun oleh masyarakat sekelilingnya. Kita tidak dapat mendidik anak-anak berbuat susila jika kita sendiri tidak sanggup menjelmakan unsur -unsur kesusilaan itu.

Pembelajaran merupakan suatu proses yang dilakukan secara sadar pada setiap individu atau kelompok untuk merubah sikap dari tidak tahu menjadi tahu sepanjang hidupnya. Sedangkan proses belajar mengajar merupakan kegiatan pokok sekolah yang di dalamnya terjadi proses siswa belajar dan guru mengajar dalam konteks interaktif dan terjadi interaksiedukatif antara.

guru dan siswa, sehingga terdapat perubahan dalam diri siswabaik perubahan pada tingkat pengetahuan, pemahaman dan keterampilan ataupun sikap. Melalui proses mengajar tersebut akan dicapai tujuan pendidikan tidak hanya dalam hal membentuk perubahan tingkah laku dalamdiri siswa, akan tetapi juga meningkatkan pengetahuan yang ada dalam diri siswa.

Kurikulum dalam pendidikan mempunyai fungsi sebagai alat untuk mencapai tujuan pendidikan. Pendidikan suatu bangsa dengan bangsa lain tidak akan sama karena setiap bangsa dan negara mempunyain filsafat dan tujuan pendidikan tertentu yang dipengaruhi oleh berbagai segi, baik segi agama, ideology, kebudayaan maupun kebutuhan negara itu sendiri.Pada Pasal 2 tentang tujuan pendidikan di negara kita berdasarkan falsafah pancasila dan UUD 1945.Untuk mewujudkan semua itu juga perlu yang namanya system pendidikan yang merupakan suatu keseluruh yang terpadu dari semua satuan kegiatan pendidikan yang berkaitan satu dengan yang lainnya. Dalam Pasal 4 berbunyi : pendidikan dan pengajaran berdasarkan atas asas-asas yang termasuk dalam pancasila Undang-Undang Dasar RI dan kebudayaan bangsa Indonesia.

Guru tidak hanya berfungsi sebagai pelaksana kurikulum tetapi juga sebagai pengembangan kurikulum dalam rangka pelaksanaan kurikulum tersebut. Dengan suasana yang nyaman dalam proses belajar mengajar memberi ketentraman dan ketenangan dalam diri murid sehingga muncul motivasi belajar yang tinggi dimana motivasi belajar merupakan kekuatan mental yang mendorong proses belajar mengajar lebih aktif dan menyenangkan. Intelegensi dianggap sebagai suatu norma umum dalam keberhasilan belajar. Intelegensi dapat diartikan sebagai suatu kemampuan yang abstrak dari seseorang untuk memecahkan problema yang dihadapi dalam kehidupan sehari-hari. Sifat-sifat pribadi seseorang yang sering disebut kepribadian juga turut memperoleh peran dalam belajar. Tiap orang mempunyai sifat pribadi atau kepribadian antara yang satu dengan yang lain sehingga kepribadian yang ada pada diri seseorang itu sedikit banyak mempengaruhi keberhasilan belajarnya.

Pendidkan saat ini, guru seringkali mendapatkan kesulitan dalam pembelajaran. Misalnya: siswa merasa bosan ketika pembelajaran berlangsung karena tidak ada yang membuat semangat dalam pembelajaran tersebut. Hal ini menyebabkan kurang aktifnya siswa dalam kegiatan pembelajaran, apalagi pada pelajaran yang dianggapnya sulit. Oleh karena itu, peneliti mencoba membuat siswa lebih aktif di dalam kegiatan pembelajaran, dan meningkatkan semangat belajar dalam diri siswa. Dalam penelitian ini peneliti menggunakan pendekatan 
active learning dengan metode poster comment. Peneliti berharap dengan metode ini bisa menumbuhkan motivasi belajar siswa dalam pembelajaran.

Pentingnya motivasi dalam belajar merupakan bahan kajian yang menarik bagi guru sekaligus mengandung konsekuensi, bahwa para guru perlu mempunyai wawasan yang mendalam mengenai pembelajaran yangmenyenangkan dan efektif agar dapat membantu dalam meningkatkan motivasi belajar para siswa khususnya belajar dalam bidang studi PKn.

Kelemahan-kelemahan tersebut diperberat lagi oleh beberapa kondisi yang ada, diantaranya masih berlakunya sistem guru kelas harus mengajarkan beberapamata pelajaran. Masingmasing mata pelajaran itu mempunyai karakteristik atau ciritersendiri.

Agar pembelajaran PKn ini bisa maksimal dan diminati oleh siswa,maka pelaksanaan pembelajaran haruslah menyenangkan dan menantang. Untuk itu para guru harus mampu membangkitkan semangat siswa dan menjadikan siswa merasa mengalami sendiri apa yang disampaikan oleh guru, sehingga siswa merasa tertantang untuk menggali pengalamanya. Dengan demikian, diharapkan setiap siswa akan merasa senang mengikuti pelajaran PKn.

Strategi pembelajaran Inquiry Discovery Learning merupakan srtategi belajar mengajar yang menekankan pada siswa untuk belajar mencari dan menemukan sendiri.Dalam strategi belajar mengajar ini penyajian bahan pelajaran oleh guru tidak dalam bentuk final,tetapi siswa diberi peluang mencari penemuan-penemuan tentang mata pelajaran terkait dengan mempergunakan teknik pendekatan pemecahan masalah.

Meminjam pendapat Bruner dalam Trianto (2010:91), bahwa berusaha sendiri untuk mencari pemecahan masalah serta pengetahuan yang menyertainya, menghasilan pengetahuan yang benar-benar bermakna. Teknik pendekatan ini merupakan medium yang luwes, sehingga berbagai maksud dan tujuan pembelajaran dapat tercapai, sebab teknik ini menyenangkan.
Dengan penerapan strategi pembelajaran Inquiry Discovery Learning diharapkan dapat mempengaruhi tingkat motivasi, konsentrasi kecepatan menyerap materi pelajaran, serta kematangan pemahaman terhadap materi pelajaran.Berdasarkan observasi awal dan wawancara langsung penulis pada siswa kelas IV diketahui bahwa dalam kegiatan pembelajaran terlihat motivasi belajar siswa pada mata pelajaran PKn sangat rendah. Kondisi ini terlihat dari sikap siswa yang kurang perhatian pada mata pelajaran tersebut. Hal ini disebabkan karena monotonnya pendekatan pembelajaran yang gunakan oleh guru dan minimnya media pembelajaran yang digunakan. Selain itu terbatasnya jam pelajaran untuk pembelajaran PKn juga berpengaruh besar terhadap motivasi belajar siswa.

Berdasarkan pada permasalahan tersebut di atas, maka penulis mencoba untuk meneliti pengaruh metode Inquiry Discovery Learning dalam proses pembelajaran PKn di kelas IV 139 Kecamatan Duampanua Kabupaten Pinrang. Dengan penerapan strategi pembelajaran Inquiry Discovery Learning diharapkan dapat mempengaruhi tingkat motivasi, konsentrasi kecepatan menyerap materi pelajaran, serta kematangan pemahaman terhadap materi pelajaran.

\section{METODE PENELITIAN}

Penelitian Penelitian ini dilakukan di SDN 139 Duampanua yang terletak dikecematan duampanua kabupaten pinrang.Dasar pertimbangan pengambilan lokasi dikarenakan di SDN 139 duampanua hasil belajar PKn masih rendah dan system pembelajaran guru lebih aktif daripada siswa.

Desain penelitian yang digunakan dalam penelitian ini desain jenis One-Group PretestPosttest Design.Dalam penelitian ini hasil perlakuan dapat diketahui lebih akurat, karena dapat membandingkan dengan keadaan sebelum dan sesuda diberi perlakuan.Adapun desain penelitian ini sebagai berikut. 
Desain Penelitian

$$
\mathrm{O}_{1} \mathrm{XO}_{2}
$$

Sumber : Emzir,2014

Keterangan :

$\mathrm{O}_{1} \quad$ : Tes awal (pretest)

$\mathrm{O}_{2} \quad$ : Tes akhir (posttest)

$\mathrm{X}$ : Perlakuan dengan menggunakan model pembelajaran.

Model eksperimen ini melalui tiga langkah yaitu :

1. Memberikan pretest untuk mengukur variable terikat (hasil belajar) sebelum perlakuan diberikan.

2. Memberikan perlakuan kepada kelas subjek penelitian dengan menerapkan metode Inquiry Discoveri Learning.

3. Memberikan posttest untuk mengukur variable terikat setelah perlakuan dilakukan.

Populasi penelitian ini adalah siswa kelas IV SDN 139 Kecamatan Duampanua Kabupaten Pinrang dengan siswa sebanyak 32 orang diantaranya 14 laki-laki dan 18 perempuan. Sampel penelitian terdiri atas semua populasi kelas IV SDN 139 Kecamatan Duampanua Kabupaten Pinrang yang berjumlah 32 siswa dengan menggunakan teknik penelitian eksperimen. Dalam penelitian ini metode yang akan digunakan yaitu observasi, tes hasil belajar dan dokumentasi. Sumber data dalam penelitian ini adalah murid kelas IV SDN 139 Kecamatan Duampanua Kabupaten Pinrang. Data yang diperoleh dianalisis dengan menggunakan teknik analisis statistik deskriptif dan analisis korelasi product momemt untuk pengujian hipotesis, yang sebelumnya didahului dengan uji persyaratan analisis uiji normalitas data.

Analisis Statistik Deskriptif

Statistik deskrptif adalah statistik yang berfungsi untuk memdeskripsikan atau memberi gambaran terhadap obyek yang diteliti melalui data sampel dan populasi sebagaimana adanya.

Analisis deskriptif ini untuk menggambarkan Pengaruh Metode Inqury Discoveri Learning terhadap hasil belajar siswa dengan membuat table distribusi frekuensi dan persentase dengan rumus persentase untuk memperoleh gambaran umum mengenai pengaruh hasil belajar PKn murid kelas IV

SDN 139 kecamatan Duampanua Kabupaten Pinrang, maka dilakukan perhitungan rata-rata skor kedua variable dengan rumus sebagai berikut.

$$
\begin{aligned}
& M e=\underline{n} \text { Xi } \\
& \text { keterangan }: \\
& \text { Me }=\text { Mean ( rata-rata ) } \\
& \mathrm{Xi}=\text { Nilai } \mathrm{X} \text { ke I sampai } \mathrm{n} \\
& \mathrm{n} \quad=\text { jumlah sampel }
\end{aligned}
$$

Uji Hipotesis

Uji hipotesis penelitian tentang hubungan antara pengaruh metode Inquiry Discoveri Learning dengan hasil belajar PKn murid kelas IV SDN 139 Kecamatan Duampanua Kabupaten Pinrang digunakan rumus Korelasi Product Moment ( $r$ ), dari Sugiyono( 2013:255) yang rumusnya:

$$
\frac{r=n \sum X Y-\left(\sum X\right)\left(\sum Y\right)}{\sqrt{n \sum X^{2}-\sum X^{2}} \sqrt{n \sum Y^{2}-\left(\sum Y\right)^{2}}}
$$

Keterangan :

$r=$ Koefisien korelasi $X$ dan $Y$

$\mathrm{n}=$ Jumlah responden sebagai sampel

$X=$ Total jumlah dari variable $X$

$Y=$ Total jumlah dari variable $Y$

$\sum x^{2}=$ Jumlah nilai variable $X$

$\Sigma y^{2}=$ Jumlah nilai Hasil variable $Y$

$\Sigma x y=$ Hasil kali variable $X$ dan $Y$

\section{Tabel 3.1 Pedoman Interpretasi Terhadap} Koefisiean Korelasi

\begin{tabular}{cc}
\hline Interval Koefisien & Tingkat Hubungan \\
\hline $0,00-0,199$ & Sangat rendah \\
\hline $0,20-0,399$ & Rendah \\
\hline $0,40-0,599$ & Sedang \\
\hline $0,60-0,799$ & Kuat \\
\hline $0,80-1,000$ & Sangat kuat \\
\hline Sumber : sugiyono ( $2013: 231)$
\end{tabular}




\section{PEMBAHASAN}

Tingkat Hasil Belajar PKn Murid Pada Kelas Eksperimen Sebelum diberikan Perlakuan (Treatment) atau Pretest

Untuk memberikan gambaran awal tentang hasil belajar PKn murid pada kelas IV SDN 139 Kecamatan Duampanua Kabupaten Pinrang yang dipilih sebagai kelas eksperimen.Berkut disajikan skor hasil belajar PKn murid kelas IV kecamatan Duampanua Kabupaten Pinrang sebelum diberikan perlakuan.

Tabel 1 hasil belajar sebelum diberikan perlakuan

\begin{tabular}{cc}
\hline Statistik Deskriptif & Nilai Statistik \\
\hline Banyaknya Sampel & 32 \\
\hline Nilai Tertinggi & 80 \\
\hline Nilai Terendah & 40 \\
\hline Skor Ideal & 100 \\
\hline Rentang Skor & 40 \\
\hline Skor Rata-rata & 60,31 \\
\hline Standar Deviasi & 61,4
\end{tabular}

Sumber: Hasil olah hasil belajar murid

Berdasarkan tabel 1 menunjukkan bahwa rata-rata skor hasil belajar pendidikan kewarganegaraan murid sebelum dilakukan perlakuan (Pretest) adalah 60,31 dari skor ideal 100.Skor tertinggi yang dicapai murid adalah 80 . Dan skor terendah adalah 40, dengan standar deviasi 11,90 yang berarti bahwa skor hasil belajar PKn murid pada pretest di SDN 139 Kecamatan Duampanua Kabupaten Pinrangtersebut dari skor terendah 40 sampai pada skor tertinggi 80 . Jika skor tes hasil belajar PKn murid sebelum perlakuan (pretest) dikelompokkan ke dalam lima kategori, maka diperoleh distribusi skor frekuensi dan persentase yang ditunjukkan pada table 4.2 berikut:

Tabel 2 Distribusi dan Persentase Skor Hasil Belajar Sebelum diberikan Perlakuan (Treatment).

\begin{tabular}{lllcc}
\hline No & Skor & Kategori & Frekuensi & Persentase (\%) \\
\hline $\mathbf{1}$ & $0-54$ & Sangat & 9 & 28,125 \\
$\mathbf{2}$ & $55-64$ & Rendah & 8 & 25 \\
$\mathbf{3}$ & $65-79$ & Rendah & 14 & 43,75 \\
$\mathbf{4}$ & $80-89$ & Sedang & 1 & 3,125 \\
$\mathbf{5}$ & $90-100$ & Tinggi & 0 & 0 \\
& & Sangat & & \\
& & Tinggi & & $\mathbf{1 0 0}$ \\
\hline
\end{tabular}

Sumber: Hasil olah hasil belajar murid
Berdasarkan Tabel 1 dan Tabel 2 dapat digambarkan bahwa dari 32 murid kelas IV SDN 139 Kecamatan Duampanua Kabupaten Pinrang yang hasil Pretest, pada umumnya memiliki tingkat hasil belajar PKn dalam kategori sangat rendah dengan skor rata-rata 60,31 dari skor ideal 100 . Kemudian untuk melihat persentase ketuntasan belajar PKn murid sebelum perlakuan (Pretest) dapat dilihat pada table 4.3 berikut.

Tabel 3 Deskripsi Ketuntasan Belajar Pada Pretest

\begin{tabular}{clcc} 
Skor & Kategorisasi & Frekuensi & $\begin{array}{c}\text { Persentase } \\
\text { (\%) }\end{array}$ \\
\hline $\mathbf{7 0 - 1 0 0}$ & Tuntas & 11 & 34,375 \\
\hline $\mathbf{0 - 6 9}$ & Tidak Tuntan & 21 & 65,625 \\
\hline & Jumlah & $\mathbf{3 2}$ & $\mathbf{1 0 0}$
\end{tabular}

Sumber: Hasil olah hasil belajar murid

Berdasarkan table 3 sebelum perlakuan (Pretest)dapat digambarkan bahwa yang telah mencapai ketuntasan sebanyak 11 murid dari jumlah keseluruhan 32 murid dengan persentase $34,375 \%$ sedangkan yang tidak mencapai ketuntasan belajar sebanyak 21 murid dari jumlah keseluruhan 32 murid dengan persentase $65,625 \%$.

\section{Tingkat Hasil Belajar PKn Murid Pada Kelas Eksperimen Setelah diberikan Perlakuan (Treatment) atau Posttest}

Berikut disajikan deskripsi dan persentase hasil belajar PKn murid kelas IV SDN 139 Kecamatan Duampanua Kabupaten Pinrang setelah diberikan perlakuan atau posttest.

Tabel 4 DeskripsiSkor Hasil Belajar PKnMurid Kelas IV SDN 139 Kecamatan Duampanua Kabupaten Pinrang Setelah diberikan Perlakuan (Treatment) atau Posttest

\begin{tabular}{cc}
\hline Statistik Deskriptif & Nilai Statistik \\
\hline Banyaknya Sampel & 32 \\
\hline Nilai Tertinggi & 90 \\
\hline Nilai Terendah & 60 \\
\hline Skor Ideal & 100 \\
\hline Rentang Skor & 20 \\
\hline Skor Rata-rata & 75,46 \\
\hline Standar Deviasi & 75,4
\end{tabular}

Sumber: Hasil olah hasil belajar murid

Berdasarkan tabel 4 menunjukkan bahwa rata-rata skor hasil belajar pendidikan kewarganegaraan muridyang diajarkan dengan 
menggunakan metode Inquiry Discoveri Learning adalah 75,46 dari skor ideal 100 . Skor tertinggi yang dicapai murid adalah 90. Dan skor terendah adalah 60, dengan standar deviasi 6.00 yang berarti bahwa skor hasil belajar PKn murid pada posttest di SDN 139 Kecamatan Duampanua Kabupaten Pinrangterbesar dari skor terendah 60 sampai pada skor tertinggi 90. Jika skor tes hasil belajar PKn murid yang diajarkan dengan menggunakan metode Inquiri Discoveri Learning dikelompokkan ke dalam lima kategori, maka diperoleh distribusi skor frekuensi dan persentase yang ditunjukkan pada table 4.5berikut :

Tabel 5 Distribusi dan Persentase Skor Hasil Belajar Setelah diberikan Perlakuan (Treatment) atau Posttest

\begin{tabular}{cclcc}
\hline No & Skor & Kategori & Frekuensi & $\begin{array}{c}\text { Persentase } \\
(\%)\end{array}$ \\
\hline $\mathbf{1}$ & $0-54$ & Sangat & 0 & 0 \\
$\mathbf{2}$ & $55-64$ & Rendah & 0 & 0 \\
$\mathbf{3}$ & $65-79$ & Rendah & 21 & 65,625 \\
$\mathbf{4}$ & $80-89$ & Sedang & 10 & 31,25 \\
$\mathbf{5}$ & $90-100$ & Tinggi & 1 & 3,125 \\
& & Sangat & & \\
& & Tinggi & $\mathbf{3 2}$ & $\mathbf{1 0 0}$ \\
\hline \multicolumn{5}{c}{ Jumlah }
\end{tabular}

Sumber: Hasil olah hasil belajar murid

Berdasarkan Tabel 4 dan Tabel 5 dapat digambarkan bahwa dari 32 murid kelas IV SD 139 Kecamatan Duampanua Kabupaten Pinrang yang dijadikan sampel penelitian Posttest, pada umumnya memiliki tingkat hasil belajar PKn dalam kategori sangat rendah dengan skor rata-rata 75,46 dari skor ideal 100.Kemudian untuk melihat persentase ketuntasan belajar PKn murid setelah perlakuan (Posttest) dengan menggunakan metode Inquiry Discoveri Learning dapat dilihat pada table 6 berikut.

Tabel 4.6 Deskripsi Ketuntasan Belajar PKn Setelah diberikan Perlakuan (Treatment) atau Posttest

\begin{tabular}{cccc}
\hline Skor & Kategorisasi & Frekuensi & Persentase (\%) \\
\hline $\mathbf{7 0 - 1 0 0}$ & Tuntas & 30 & 93,75 \\
\hline $\mathbf{0 - 6 9}$ & Tidak Tuntan & $\mathbf{2}$ & 6,25 \\
\hline & Jumlah & $\mathbf{3 2}$ & $\mathbf{1 0 0}$
\end{tabular}

Sumber: Hasil olah hasil belajar murid

Berdasarkan table 6 setelah perlakuan (Posttest) dengan menggunakan metode Inquiry Discoveri Learning dapat digambarkan bahwa yang telah mencapai ketuntasan sebanyak 30 murid dari jumlah keseluruhan 32 murid dengan persentase 93,75\% sedangkan yang tidak mencapai ketuntasan belajar sebanyak 2 murid dari jumlah keseluruhan 32 murid dengan persentase $6,25 \%$. Apabila table 4.6 dikaitkan dengan indicator ketuntasan hasil belajar murid maka dapat disimpulkan bahwa hasil belajar PKn murid kelas IV SD 139 Kecamatan Duampanua Kabupaten Pinrang setelah diterapkan dengan menggunakan metode Inquiry Discoveri Learning sudah memenuhi indicator ketuntasan hasil belajar secara klasikal.

Perbandingan Tingkat Hasil Belajar Murid Kelas Eksperimendengan menggunakan Metode Inquiry Discoveri Learning antara dengan tidak menggunakakan Metode Inquiry Discoveri Learning

Perbedaan hasil belajar murid sebelum dilaksanakan perlakuan (Pretest) dan setelah dilaksanakan perlakuan (Posttest) pada kelas eksperimen dengan menggunakan metode Inquiry Discoveri Learning antara tidak menggunkan metode inquri discoveri learning yang ditunjukkan Tabel 7 berikut ini:

Tabel 7 Distribusi Hasil Belajar Murid Pretest dan Posttest.

\begin{tabular}{ccc}
\hline Statistik & \multicolumn{2}{c}{ Nilai Statistik } \\
\cline { 2 - 3 } & Pretest & Posttest \\
\hline Ukuran Sampel & 32 & 32 \\
Skor Tertinggi & 80 & 90 \\
Skor Terendah & 40 & 60 \\
Skor Ideal & 100 & 100 \\
Rentang Skor & 40 & 20 \\
Skor Rata-rata & 60,31 & 75,46 \\
Standar Deviasi & 61,4 & 75,4
\end{tabular}

Sumber: Hasil olah seluruh hasil belajar murid

Dari table 7 di atas digambarkan bahwa skor tertinggi hasil Pretest pada kelas yang menggunakan metode Inquiry Discoveri Learning dalam pembelajaran dan yang tidak menggunakan metode Inquiry Discoveri Learning dalam pembelajaran belum mencapai skor ideal. Sementara pada hasil Posttest, pada kelas yang menggunakan metode Inquiry Discoveri Learning dalam pembelajaran skor tertinggi mencapai skor ideal dan pada kelas yang tidak menngunakan metode Inquiry Discoveri Learning dalam 
pembelajaran skor tertinggi belum mencapai skor maksimal atau skor ideal.

Rata-rata hasil pretest dan posttest pada kelas IV SDN 139 Kecamatan Duampanua Kabupaten Pinrang setelah diberi perlakuan dan tidak diberi perlakuan memiliki hasil yang berbeda. Rata-rata hasil pretest sebelum diberikan perlakuan pada murid yaitu 61,66 dari jumlah 32 murid sedangkan hasil posttest setelah diberikan perlakuan pada murid yaitu 75,46 dari 32 jumlah murid. Sehingga dapat disimpulkan bahwa hasil belajar PKn murid dengan menggunakan metode Inquiry Discoveri Learning lebih baik daripada tidak menggunakan metode Inquiry Discoveri Learning.

\section{Pengujian Hipotesis}

Pada bagian terdahulu telah dikemukakan bahwa untuk menguji hipotesis digunakan rumus korelasi product moment.

Tabel 8 Pengaruh Metode Inquiry Discoveri Learning dengan Hasil Belajar PKn.

\begin{tabular}{|c|c|c|}
\hline KODE SAMPEL & PENGARUH & HASIL BELAJAR \\
\hline 01 & 60 & 75 \\
\hline 02 & 40 & 70 \\
\hline 03 & 60 & 75 \\
\hline 04 & 40 & 65 \\
\hline 05 & 50 & 70 \\
\hline 06 & 60 & 75 \\
\hline 07 & 70 & 85 \\
\hline 08 & 70 & 80 \\
\hline 09 & 40 & 70 \\
\hline 10 & 65 & 75 \\
\hline 11 & 50 & 70 \\
\hline 12 & 60 & 80 \\
\hline 13 & 60 & 80 \\
\hline 14 & 40 & 75 \\
\hline 15 & 70 & 85 \\
\hline 16 & 60 & 80 \\
\hline 17 & 70 & 75 \\
\hline 18 & 75 & 75 \\
\hline 19 & 70 & 65 \\
\hline 20 & 75 & 70 \\
\hline 21 & 65 & 75 \\
\hline 22 & 60 & 80 \\
\hline 23 & 70 & 85 \\
\hline 24 & 80 & 80 \\
\hline 25 & 65 & 75 \\
\hline 26 & 75 & 90 \\
\hline 27 & 45 & 70 \\
\hline 28 & 60 & 70 \\
\hline 29 & 70 & 80 \\
\hline 30 & 65 & 70 \\
\hline 31 & 40 & 75 \\
\hline 32 & 50 & 70 \\
\hline
\end{tabular}

Tabel 8 dapat ditindak lanjuti guna memcari Koefisien Korelasi antara Pengaruh Metode sebagai variable $\mathrm{X}$ terhadap hasil belajar PKn murid kelas IV SDN 139 Kecamatan Duampanua Kabupaten Pinrang sebagai variable $\mathrm{Y}$.

Tabel 9 Analisis Deskriptif Data Hasil Penelitian Pengaruh Metode dan Hasil Belajar PKn.

\begin{tabular}{|c|c|c|c|c|c|}
\hline KODE & $X$ & $\mathrm{Y}$ & $X^{2}$ & $Y^{2}$ & $\mathrm{XY}$ \\
\hline 01 & 60 & 75 & 3600 & 5625 & 4500 \\
\hline 02 & 40 & 70 & 1600 & 2500 & 2800 \\
\hline 03 & 60 & 75 & 3600 & 5625 & 3600 \\
\hline 04 & 40 & 65 & 1600 & 4225 & 2600 \\
\hline 05 & 50 & 70 & 2500 & 4900 & 3500 \\
\hline 06 & 60 & 75 & 3600 & 5625 & 4500 \\
\hline 07 & 70 & 85 & 4900 & 7225 & 5950 \\
\hline 08 & 70 & 80 & 4900 & 6400 & 5600 \\
\hline 09 & 40 & 70 & 1600 & 4900 & 2800 \\
\hline 10 & 65 & 75 & 4225 & 5625 & 4875 \\
\hline 11 & 50 & 70 & 2500 & 4900 & 3500 \\
\hline 12 & 60 & 80 & 3600 & 6400 & 4800 \\
\hline 13 & 60 & 80 & 3600 & 6400 & 4800 \\
\hline 14 & 40 & 75 & 1600 & 5625 & 3000 \\
\hline 15 & 70 & 85 & 4900 & 7225 & 5950 \\
\hline 16 & 60 & 80 & 3600 & 6400 & 4800 \\
\hline 17 & 70 & 75 & 4900 & 5625 & 5250 \\
\hline 18 & 75 & 75 & 5625 & 5625 & 5625 \\
\hline 19 & 70 & 65 & 4900 & 4900 & 4550 \\
\hline 20 & 75 & 70 & 5625 & 4900 & 5250 \\
\hline 21 & 65 & 75 & 4225 & 5625 & 4875 \\
\hline 22 & 60 & 80 & 3600 & 6400 & 4800 \\
\hline 23 & 70 & 85 & 4900 & 7225 & 5950 \\
\hline 24 & 80 & 80 & 6400 & 6400 & 6400 \\
\hline 25 & 65 & 75 & 4225 & 5625 & 4875 \\
\hline 26 & 75 & 90 & 5625 & 8100 & 6750 \\
\hline 27 & 45 & 70 & 2025 & 4900 & 3150 \\
\hline 28 & 60 & 70 & 3600 & 4900 & 4200 \\
\hline 29 & 70 & 80 & 4900 & 6400 & 5600 \\
\hline 30 & 65 & 70 & 4225 & 4900 & 4550 \\
\hline 31 & 40 & 75 & 1600 & 5625 & 3000 \\
\hline \multirow[t]{2}{*}{32} & 50 & 70 & 2500 & 4900 & 3500 \\
\hline & $\begin{array}{r}\sum X= \\
1930\end{array}$ & $\begin{array}{l}\sum \mathrm{Y}= \\
2415\end{array}$ & $\begin{array}{l}\sum x^{2}= \\
120800\end{array}$ & $\begin{array}{l}\sum Y^{2}= \\
181650\end{array}$ & $\begin{array}{l}\sum X Y= \\
145900\end{array}$ \\
\hline
\end{tabular}

Berdasarkan hasil dari perhitungan pada tabel diatas, dapat diketahui sebagai berikut:

$N=32$

$\sum x=1930$

$\Sigma y=2415$

$\sum x^{2}=120800$

$\sum y^{2}=181650$ 
$\sum x y=145900$

$\sum(x)^{2}=3724900$

$\Sigma(y)^{2}=5832225$

Selanjutnya, dapat dicari koefisien antara variebel $\mathrm{X}$ dan $\mathrm{Y}$ dengan menggunakan rumus korelasi product moment dengan rumus sebagai berikut

Rumus

$\mathrm{R}=\mathrm{n} \sum \mathrm{XY}-\left(\sum \mathrm{X}\right)\left(\sum \mathrm{Y}\right)$

$$
\begin{aligned}
\sqrt{\mathrm{n} \sum \mathrm{X}^{2}-\left(\sum \mathrm{X}\right)^{2}} & \sqrt{n \sum Y^{2}-(X Y)^{2}} \\
& =32 \times 145900-(1930)
\end{aligned}
$$

(2415)

$$
\begin{aligned}
& \sqrt{32 X 120800-3724900} \sqrt{32 X 181650-5832225} \\
& =4668800-4660950
\end{aligned}
$$

$$
\begin{aligned}
& \sqrt{(140700)(5229575)} \\
& =7850 \\
& \sqrt{735801202500} \\
& =36276 \\
& 857788 \\
& =0,42
\end{aligned}
$$

Hasil analisis data memperlihatkan bahwa dari 32 siswa yang memjadi sampel penelitian, maka diperoleh nilai $r_{\text {hitung }}$ sebesar 0.42. Untuk mengetahui niliaai pengujian hipotesis maka penelitian maka nilai $r_{\text {hitung }}$ dibandinkan dengan nilai $r_{\text {tabel }}$ pada taraf $5 \%$. Kriteria ketuntasan hipotesis adalah sebagai berikut:

1. Apabila nilai $r_{\text {hitung }}$ lebih besar dari pada $r_{\text {tabel }}$ maka hoptesis diterima

2. Apabila nilai $r_{\text {hitung }}$ lebih kecil pada $r_{\text {tabel }}$ maka hipotesis ditolak

3. Nilai $r_{\text {tabel }}$ yang digunakan sebagai pembanding yaitu diketahui dengan cara memcari nilai yang berada pada titik pertemuan antara kepercayaan $5 \%$ dan $\mathrm{N}: 32$

Setelah nilai-nilai dihubungkan berdasarkan analisis data diatas, maka terlihat bahwa nilai olahan data Pengaruh Metode dengan Hasil Belajar PKn murid Kelas IV SDN 139 Kecamatan Duampanua Kabupaten Pinrang adalah 0.42 karena tidak ada N:32 dalam tabel nilai-nilai $r$ product moment, maka diambil $\mathrm{N}$ yang memdekati dari nilai signifikan $5 \%$ yaitu sebanyak 0,42

Hal ini membuktikan bahwa nilai analisis data lebih baik atau lebih besar dari pada nilai $r_{\text {tabel }}$, maka hipotesis yang diajukan dalam penelitian ini diterima dan terdapat hubungan antara Pengaruh Metode Inquiry Discoveri Learning dengan Hasil Belajar PKn murid kelas IV SDN 139 Kecamatan Duampanua Kabupaten Pinrang dengan hasil olahan data dari nilai hubungan Pengaruh Metode Inquiry Discoveri Learning dengan Hasil BelajarPKn dengan nilai 0,42 lebih besar dari nilai tabel product moment yaitu 0,40 .

\section{Deskripsi Aktivitas Siswa dalam Pembelajaran}

Lembar pengamatan ini dibuat untuk memperoleh salah satu jenis data pendukung kriteria keefektifan pembelajaran.Instrumen

\begin{tabular}{|c|c|c|c|c|c|}
\hline \multirow{2}{*}{$\begin{array}{l}\mathrm{N} \\
\mathrm{o}\end{array}$} & \multirow[t]{2}{*}{ Komponen yang diamati } & \multicolumn{2}{|c|}{$\begin{array}{l}\text { Frekuensi } \\
\text { Aktivitas }\end{array}$} & \multicolumn{2}{|l|}{ (\%) } \\
\hline & & 1 & II & 1 & II \\
\hline 1 & $\begin{array}{l}\text { Siswa yang disiplin pada } \\
\text { saat proses } \\
\text { pembelajaran } \\
\text { berlangsung }\end{array}$ & 28 & 30 & $87,5 \%$ & $\begin{array}{l}93 . \\
75 \%\end{array}$ \\
\hline 2 & $\begin{array}{l}\text { Siswa yang } \\
\text { memperhatikan guru } \\
\text { pada saat proses } \\
\text { pembelajaran } \\
\text { berlangsung }\end{array}$ & 25 & 29 & $78,125 \%$ & $\begin{array}{c}90 \\
525 \\
\%\end{array}$ \\
\hline 3 & $\begin{array}{l}\text { Siswa yang aktif bertanya } \\
\text { pada saat proses } \\
\text { pembelajaran }\end{array}$ & 15 & 28 & $46,875 \%$ & $\begin{array}{l}87 \\
5 \%\end{array}$ \\
\hline 4 & $\begin{array}{l}\text { Siswa yang antusias } \\
\text { menggunakan metode } \\
\text { inquiry discoveri learning }\end{array}$ & 28 & 29 & $87,5 \%$ & $\begin{array}{c}90 \\
525 \\
\%\end{array}$ \\
\hline 5 & $\begin{array}{l}\text { Siswa yang memahami } \\
\text { materi yang diajarkan }\end{array}$ & 25 & 30 & $78,125 \%$ & $\begin{array}{l}93 \\
75 \%\end{array}$ \\
\hline
\end{tabular}
lembar observasi ini memuat 8 indikator aktivitas siswa.Pengamatan dilaksankan oleh observer mengamati aktifitas siswa yang dilakukan selama dua kali pembelajaran.Data yang diperoleh dari instrumen tersebut dirangkum pada setiap akhir pertemuan. Hasil rangkuman pengamatan disajikan pada Tabel 4.8 berikut ini:

Tabel 10 Persentase Aktivitas Siswa Kelas Eksperimen dalam Pembelajaran

$\begin{array}{lllll}6 & \text { Siswa yang mengerjakan } \quad 29 \quad 32 & 90,525 \% & 100\end{array}$ 


\begin{tabular}{|c|c|c|c|c|c|}
\hline & $\begin{array}{l}\text { tugas yang telah } \\
\text { diberikan }\end{array}$ & & & & $\%$ \\
\hline 7 & $\begin{array}{l}\text { Siswa yang melakukan } \\
\text { aktivitas lain yang tidak } \\
\text { relevan saat proses } \\
\text { pembelajaran } \\
\text { berlangsung }\end{array}$ & 8 & 10 & $25 \%$ & $\begin{array}{c}31 \\
25 \%\end{array}$ \\
\hline 8 & $\begin{array}{l}\text { Siswa yang masih perlu } \\
\text { bimbingan dalam } \\
\text { memahami }\end{array}$ & 10 & 6 & $33,33 \%$ & $\begin{array}{c}23 \\
33 \%\end{array}$ \\
\hline
\end{tabular}

Sumber: Hasil olah data

Aktifitas siswa pada saat pembelajaran menggunakan metode Inquiry Discoveri Learning:

1. Persentase kedisiplinan siswa pada saat proses pembelajaran yaitu $93,75 \%$.

2. Persentase siswa yang memperhatikan guru pada saat proses pembelajaran berlangsung yaitu $90,525 \%$

3. Persentase siswa yang aktif bertanya pada saat proses pembelajaran yaitu $87,5 \%$

4. Persentase siswa yang antusias menggunakan metode inquiry discoveri learning yaitu $90,525 \%$

5. Persentase siswa yang memahami materi yang diajarkan yaitu $93,75 \%$

6. Persentase siswa yang mengerjakan tugas yang telah diberikan yaitu $100 \%$

7. Persentase siswa yang melakukan aktivitas lain yang tidak relevan saat proses pembelajaran berlangsung yaitu $31,25 \%$

8. Persentase siswa yang masih perlu bimbingan yaitu $28,33 \%$

Rata-rata persentase aktivitas siswa terhadap pelaksanaan model pembelajaran Inquiri yaitu $45,76 \%$. Sesuai dengan indikator aktifitas siswa yaitu siswa dikatakan aktif jika sekurang kurangnya $70 \%$ siswa terlibat aktif dalam pembelajaran, sedangkan dari hasil pengamatan rata-rata persentase siswa hanya $45,76 \%$ maka aktivitas siswa belum mencapai kriteria aktif. Pembelajaran yang menggunakan metode Inquiry Discoveri Learning dan tidak menggunakan metode Inquiry Discoveri Learning akan diuraikan pembahasan hasil penelitian yang meliputi:

1. Terdapat perbedaan hasil belajar murid yang di beri perlakuan dengan murid yang tidak diberi perlakuan

2. Terdapat peningkatan hasil belajar murid setelah menggunakan metode inquiry discoveri learning, menunjukkan bahwa terdapat 30 murid atau $93,75 \%$ siswa yang mencapai ketuntasan belajar, namun sebelum diberikan perlakuan hanya 11 murid yang mencapai ketuntasan dengan persentase $34,375 \%$. Hal ini berarti dengan menggunakan metode inquiry discoveri learning dapat membantu murid dalam mencapai nilai ketuntasan.

Hasil dari guru maka pada bagian ini dapat diuraikan pembahasan hasil penelitian yang meliputi :

1. Guru hanya menggunakan model pembelajaran biasa saja atau bahkan tidak menggunakan model pembelajaran. Guru lebih banyak menggunakan model pembelajaran ceramah setelah itu pemberian tugas pada siswa.

2. Guru lebih sering menggunakan model pembelajaran ceramah karena dengan model ini seluruh siswa dapat mendengarkan materi apa yang diberikan tampa harus berdiskusi dengan temannya. Dengan diskusi murid akan ribut dan berkeliaran.

\section{KESIMPULAN}

Berdasarkan hasil penelitian tentang pengaruh Metode Inquiry Discoveri Learning terhadap hasil belajar PKn siswa kelas IV SDN 139 Kecamatan Duampanua Kabupaten Pinrang dapat disimpulkan (1) Pengaruh dalam proses belajar mengajar dengan menggunakan metode sangat membantu proses belajar mengajar siswa tercapai sesuai dengan tujuan. Awalnya banyak siswa yang memiliki skor dibawah rata-rata tetapi setelah penggunaan metode Inquiri Discoveri Learning skor diatas rata-rata hasil belajar. (2) Hasil belajar murid diSDN 139 Kecamatan Duampanua Kabupaten Pinrang dengan rata-rata 61,66 sebelum diberi perlakuan dan setelah diberi perlakuan 75,83, maka demikian hasil belajar siswa yang diperoleh suda lebih baik dari sebelumnya. Dengan adanya perubahan semangat belajar siswa semakin bertambah dan rasa ingin tahu siswapun bertambah. (3) Motivasi belajar dengan hasil belajar pada mata pelajaran PKn murid kelas IV SDN 139 Kecamatan Duampanua Kabupaten Pinrang 
menunjukkan adanya hubungan yang ditunjukkan oleh nilai $r_{\text {hitung }}$ sebesar 0,42 yang tergolong berada pada korelasi " sedang", dengan melihat tabel pedoman untuk memberikan interpretasi terhadap koefisien korelasi.

\section{DAFTAR PUSTAKA}

[1] Abu Ahmadi, Joko Tri Prasetyo, (2007). Strategi Belajar Mengajar. Bandung: Pustaka,

[2] Arikanto, Suharsimi. (2005) Prosedur Penelitian Suatu Pendekatan Praktik. Jakarta: PT Rineka Cipta.

[3] Asrori, M., (2009). Penelitian Tindakan Kelas, (Bandung: CV. Wacana Prima,

[4] Bfadal, Ibrahim. (2003). Superpisi Pengajaran: Teori Dan Aplikasi Dalam Membina Profesional Guru. Jakarta: Bumi Aksara.

[5] Brunner, (1986), Metode Inquiry Discoveri Learning, (online)halaman tersebut siakses 17 Mei 2017.

[6] Dimyati, dan Mudjiono, (2002), Prinsip Dalam Belajar.(online)halaman tersebut siakses $27 \mathrm{Mei}$ 2017

[7] Djalidkk, (1996), Pedoman Praktis Penelitiandan Penulisan Karyal Imiah Ujung Pandang :Lembaga Penelitian.

[8] Djamarah dan Zain, Aswan, (2006). Strategi Belajar Mengajar. Jakarta: Rineka Cipta,

[9] Junaidi, dkk, (2009). Pendidikan Kewarganegaraan. Surabaya; Lapis-PGMI,

[10] Mudjiono, Dimyati, (2013). Belajardan Pembelajaran. Jakarta: RinekaCipt.

[11] Murtado Amin, dkk., (2009). Pembelajaran PKn , (Surabaya: LAPIS-PGMI)

[12] Ni'ma, (2015), Pengaruh Penerapan Model Pembelajaran Inquiry Terhadap Hasil Belajar PKn Siswa Kelas V SD Impres Ana'Gowa.

[13] Riduwan, (2014), Kerangka Pikir Penelitian Dan Prosedur Penelitian Suatu Pendekan Praktik. Jakarta: PT Rineka Cipta.

[14] Sardiman, (2001), Ilmu Pendidikan, Bandung : PT. Remaja Rosada karya.

[15] Sekaran, (1992), Supe Visi Pengajaran Teori Dan Aplikasinya Dalam Membina peofesional Guru.Jakarta: Bumi Aksara.

[16] Suardi, S. (2018). Peningkatan Hasil Belajar Sosiologi Pokok Bahasan Interaksi Sosial Melalui Metode Diskusi pada Siswa Kelas X MA. Muhammadiyah Panaikang Kacamatan Bissappu Kabupten Bantaeng. " JURNAL ETIKA DEMOKRASI (JED)" PRODI PPKn FKIP UNISMUH MAKASSAR, 2(1).

[17] Sugiyono. (2015). Metode Penelitian Pendidikan. Bandung : ALFABETA.

[18] Suprijono, (2010), Model Pembelajaran Inquiry Discoveri Learning, (online) halaman tersebut diakses 27 Mei 2017.

[19] Suryosubroto, (2009), Model Pembelajaran Inquiry Discoveri Learning, (online) halaman tersebut diakses 27 Mei 2017.
[20] Susanto, (2013), Teori Belajar Pembelajaran, Jakarta :Kencana.

[21] Trianto, (2010), Model Pembelajaran,Jakarta :Bumi Aksara 2010.

[22] Zamroni, (2013), Pembelajaran Kewarganegaraan Jakarta. 